\title{
Psychological Influences on Bus Travel Mode Choice: A Comparative Analysis between Two Chinese Cities
}

\author{
Jian Chen, ${ }^{1}$ Qi Chen ${ }^{(D)}{ }^{2}$ and He-ping $\mathrm{Li}^{3}$ \\ ${ }^{1}$ College of Traffic and Transportation, Chongqing Jiaotong University, Chongqing 400074, China \\ ${ }^{2}$ College of Civil Engineering and Architecture, Henan University of Technology, Zhengzhou 450000, China \\ ${ }^{3}$ School of Architecture and Urban Planning, Chongqing University, Chongqing 400045, China
}

Correspondence should be addressed to Qi Chen; chenqi@haut.edu.cn

Received 20 April 2020; Revised 22 July 2020; Accepted 7 August 2020; Published 28 August 2020

Academic Editor: Richard S. Tay

Copyright (C) 2020 Jian Chen et al. This is an open access article distributed under the Creative Commons Attribution License, which permits unrestricted use, distribution, and reproduction in any medium, provided the original work is properly cited.

Psychological factors give an important influence on the behavior of travel mode choice, but the effects vary from different cities. To identify and explain the differences, this study makes a comparative analysis between two Chinese cities, Chongqing and Chengdu: a typical mountain city and a typical plain city. The sample is obtained by questionnaires containing 401 and 450 valid records of the two cities, respectively. The model used in this study is established based on the framework of the theory of planned behavior. The main work of this study has three aspects: (1) define the measured variables based on the combination of bus travel characteristics and the theory of planned behavior; (2) verify the model validity in both two cities; (3) make a comparative analysis on the two cities. According to the results, the validity of the theory framework and measured variables is verified; the perceived behavioral control plays the most important role in affecting the behavior of traveling by bus in both two cities; significant differences between the two cities are presented and explained.

\section{Introduction}

Private cars create much more environmental pollution-air pollution, greenhouse gases, and fossil fuel consumption-than buses [1]. The traffic congestion problems that characterize developing countries' large cities have become more and more severe and are now being experienced in medium and small cities. Consequently, there is global consensus on the need to prioritize urban public transport. Of course, urban rail transit is a good choice as well as the orientation in urban public transport, but the high construction cost and the too-large transport capacity would not suit for all the cities. Coupled with the different positioning of bus and urban rail transit, bus still plays an irreplaceable role in the urban public transport system. Understanding the factors influencing bus use is an important issue for a government to implement measures to convert private car users to bus passengers. Bus share ratios reflect the relative importance of the bus in the urban public transport system and also represent residents' travel choices.
Bus transportation is also a type of service, and the quality of service provided is thought to affect passengers' attitudes to traveling by bus. According to previous research, one's attitude toward travel mode is an important psychological factor that influences actual travel mode choice [2, 3]. However, the influence should not be the same in different types of cities due to different city characteristics, which include city sizes, city forms, and resident habits. Through reflecting the city characteristics to questionnaires, the differences between cities are supposed to be quantified in the model. To understand deeply how attitude influences travel mode choice, this study attempts to make a comparison between two cities with typically different characteristics.

This empirical study used two Chinese cities, which are Chongqing and Chengdu, one being a typical mountain city and the other a typical plain city. This study examined the psychological factors that influence people's intentions to travel by bus and compared the influences these factors have in each of these two cities, in terms of landform, culture, and 
travel preferences. The main objectives of this study were to (1) develop survey questions that will elicit responses researchers can use to measure these psychological factors, (2) identify the psychological factors that influence people to choose to travel using bus in both two cities, (3) establish and estimate a mathematical model that describes travelers' intentions to ride the bus, and (4) make comparisons of the results of two cities and give some rational explanations for the results.

The paper's content is organized as follows: Section 2 provides a literature review of the research that stated the methods used to explain bus travel intentions and clarifies how the TPB was used to formulate a general framework for studying intention and behavior; Section 3 summarizes the methods used to conduct this study; Section 4 reviews the results of the two cities and makes a comparison between them; and Section 5 discusses the study's findings, gives some rational explanation for the differences between two cities, notes the limitations encountered, and identifies scope for further research.

\section{Review}

2.1. Travel Mode Choice. Understanding the determinants of travel mode choice is a key precondition for encouraging private car users to use the bus, and so for public transport planning. Travel mode choice-the process used to determine one's means of travel-is thought to be influenced by both the traveler's characteristics and those of the travel mode. This process is usually investigated as a discrete choice problem, which is solved by quantifying the influence of specific contributing factors on travel mode choice [4-8]. According to previous studies, the factors that influence mode choice can fall into two main categories-objective and psychological attributes.

Many earlier transportation studies have endeavored to explain travel mode choices using the objective attributes. Factors such as departure frequencies, travel costs, and travel times have commonly been used to estimate mode choice preferences $[5,6,9,10]$. Attributes of the public transport service, such as convenience, reliability, comfort, and vehicle availability, were also thought to relate to travel mode choice $[11,12]$, and demographic factors, such as age, income, household size, and vehicle ownership, and their effects were verified [8, 13-15].

Although published studies have shown a significant correlation between objective attributes and mode choice behavior, motivation, and procedures, why and how the choices were made remain unclear. Recent studies, however, analyzed whether psychological attributes motivated people's choice of travel mode and found that psychological factors such as habitual car use and social status have a significant influence on travel mode choice [16-18]. Other recent studies have examined passengers' perceptions and attitudes in their choice behavior models to improve the accuracy of their predictions [19-21].

Based on a review of influencing factors in terms of different classifications, two complementary phases can be summarized to explain how travel mode choices are made
[22]. Initially, travel mode choices were measured without considering users' attitudes. The next phase of research, however, went further in explaining the motivation that led to a mode choice behavior, and previous studies have clearly shown that psychological factors (e.g., habits, trip purpose, attitude to travel modes, and social implications) can effectively supplement and even override physical factors $[23,24]$.

To investigate the effects of psychological factors, the theory of planned behavior (TPB) proposed by Ajzen [25], which argues that beliefs and behaviors are linked, is widely accepted in current research as a framework for explaining travel mode choice [16, 26-28]. This theory is comprised of five fundamental elements-behavior, intention, attitude toward the behavior, subjective norms, and perceived behavioral control (PBC) [25]. It posits that individuals' actual behaviors are directly influenced by their intentions and are entirely determined by their attitudes, SN, and perceived level of behavioral control in executing the behavior.

2.2. Applications of TPB on Travel Mode Choice. In recent years, the theory of planned behavior has received considerable attention and support in many empirical studies of social cognition models designed to predict behaviors $[25,29-32]$. An earlier review of this theory's effectiveness in explaining health-related behaviors summarized 58 such applications, in which the applications were categorized in one of seven classes (addictive, clinical/screening, driving, eating, exercising, HIV/AIDS, and oral hygiene) [33]. Though these statistical results showed that PBC plays an important role in explaining intention, and that it is also important as a variable for attitude toward the action, the results varied for different kinds of behaviors. An article based on the TPB discussed promoting a new behavior by forming an implementation intention using an application of travel mode choice [34]. The results supported the validity of this theory by interpreting the effects of the relationship between implementation intention and behavior and argued that past behavior could be another important factor affecting behavior. With scholars' acceptance and development, the TPB has become an effective tool for predicting travel mode choice.

Many modifications have been made to the TPB in an attempt to explain travel mode choice behavior more comprehensively and accurately. It could be considered a general framework for describing how intention is generated, and how behavior is decided. It is not always applicable to some behaviors, as in the domain of travel mode choice for example, when the behavior may be determined not only by self-intention but also by some external objective factors such as fare and accessibility. Thus, extensive efforts have been made to improve the effectiveness of TPB in the domain of travel mode choice. Based on the theory's framework, Hunecke et al. investigated travel mode choice from the perspective of ecological norms, while considering external aspects such as fare and subway station range [35]. Another study during the same period tested the hypothesis that interventions could influence travel mode choices, and 
the results of this study supported the argument that travel mode choice is also affected by external objective factors [27].

Although the TPB offers an available framework for analyzing the effects of the psychological factors, the quantification and observation of these factors are difficult to implement. Structural equation modeling (SEM), developed in the 1970s, provides a way to address the psychological factors by introducing unquantifiable endogenous variables that are explained by exogenous variables, as well as unobserved latent variables indicated by observed variables $[36,37]$. Applications of the standard error of the means are commonly justified in the social sciences, because of their ability to impute relationships between unobserved constructs from observable variables [38-41].

2.3. Summary. For different types of cities, due to differences in the degree of development and habits, travel-related attitudes and behaviors are very diverse, even when they have the same condition of objective attributes [42, 43]. For this reason, two research questions are proposed to this study: (1) Whether the same model framework and variable set have a consistent validity of two different cities; (2) What caused the differences between the two cities? The two cities investigated in this study have strikingly different characteristics; one is a typical mountain city where relatively fewer people ride bicycles, and the other is a typical city situated on a plain, where daily travel modes are more diverse.

As to the model's construction and estimation, this study constructs the model based on the TPB framework and adopts the SEM approach for its advantages in analyzing complex psychological issues. There are two key points that need to be dealt with, which are the development of an indicator system and the model's structure. The indicator system and the questionnaire are kept the same in both two cities, thus ensuring the credibility of the comparison.

Travel purposes and passengers' feelings, coupled with their SN and PBC, usually affect travel intentions and, thus, determine their choice of behavior. We posit that there are interactions between attitudes, SN, and PBC, as depicted in the model framework shown in Figure 1. This study examines the effects of both rationale and other factors on their travel intentions and then compares the findings from both Chongqing city (mountain city) and Chengdu city (plain city). Based on this research question and research method, a basic premise should be contained in the analysis: a higher point of the answer has a positive effect on choosing the bus mode.

\section{Methods}

3.1. Data Collection. This study compares the bus choice behaviors of residents in a typical mountainous city with those of residents in a typical plain city to investigate bus passengers in the two cities. The two cities have a similar urban area and population size; the urban area of Chongqing is $5472 \mathrm{~km}^{2}$, and the population is 8.65 million, and as to Chengdu, the urban area is $3640 \mathrm{~km}^{2}$, and the population is 10.2 million. Both cities are first-tier cities in China.
On the public transport conditions, by the end of 2018, Chongqing's subway operating mileage has reached $313.6 \mathrm{~km}$ by 8 lines, and Chengdu is $226.0 \mathrm{~km}$ by 6 lines. According to 2018 statistics, the average daily passenger traffic of Chengdu subway has exceeded 3 million passengers, and Chongqing has also exceeded 2.5 million passengers [44]. As to the bus travel volume, Chongqing has exceeded 5 million passengers per day, while Chengdu is close to 4 million. We can think that the two cities have a similar scale of subway and bus system.

On the travel characteristics, as a typical plain city, Chengdu has a relatively high transportation convenience. This also makes cycling to become an important travel mode in a short-distance trip. Additionally, recent years have seen a booming of bike-sharing in China, which now has been the first choice in short/mid-distance trip. According to data onto May 2019, Chengdu currently has more than 2 million daily average bicycle rides; the average daily cycling mileage is more than 3.6 million kilometers. The situation is thoroughly different in Chongqing; according to 2019 Chongqing Urban Traffic Annual Report, the ratio of traveling by bicycle is close to 0 , which means cycling in Chongqing is not used as a means of transportation [45].

The questionnaire used for this study was developed after the questions in an initial questionnaire had been refined and their validity tested using pretest data. For the SEM path analysis, Kline recommended there should be at least 10 cases per parameter estimated [46]. This translated to a minimum sample size of 190, which was considerably more than the minimum sample size of 95 required for multiple regression analysis [47]. For this research, 500 questionnaires were distributed in each of Chongqing and Chengdu between September and October 2018. The main survey areas were decided on the basis of crowds, such as bus stops, commercial plazas, and train stations. After excluding the returned questionnaires that had not been completed properly, which included those with more than 3 missing values, or those with more than 5 extreme responses, 851 valid questionnaires were recovered (401 in Chongqing, and 450 in Chengdu), and the effective recovery rate was $85.1 \%$.

3.2. Measures. This study used the SEM to describe causality in the explanatory variables and its quantitative influence on the decision of whether to choose the bus mode. The model in this study contains 4 latent variables; that is, attitude, $\mathrm{SN}$, and $\mathrm{PBC}$ are predicted variables, while bus travel intention is the mediator variable, and the result of the behavior is whether to travel by bus. The meanings of each latent variable are as follows:

(i) Attitude explains how individuals' positive or negative evaluations influence their bus mode choices

(ii) Subjective norms represent the social pressures felt by individuals with regard to traveling by bus

(iii) Perceived behavioral control refers to the degree to which a person believes they control any given behavior 


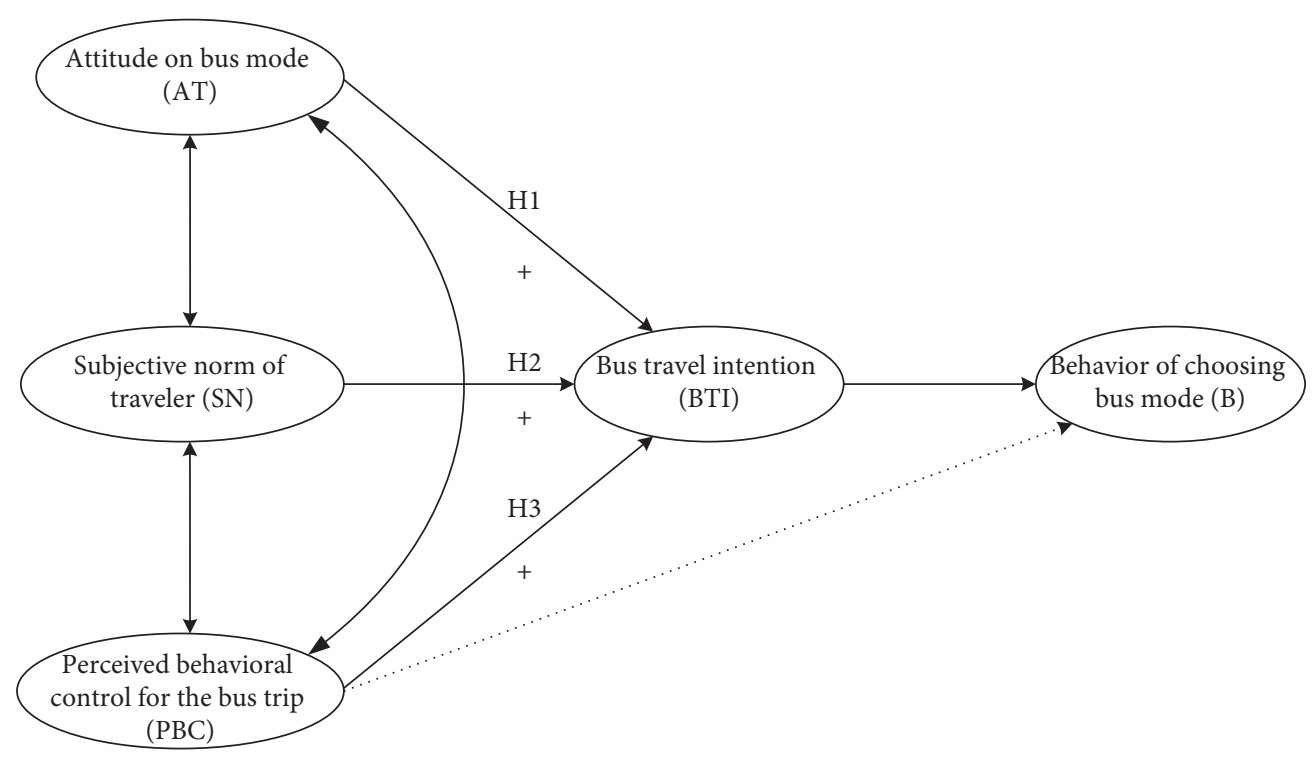

Figure 1: TPB-based model framework.

(iv) Bus travel intention reflects an individual's willingness to use the bus, and the possibility that they will encourage others to use the bus

(v) Behavior is the result of final decision

The measurement variables for each latent variable are shown in Table 1. The measurement method used was based on a Likert 7-point scale [16].

3.3. Study Participants. Statistical analysis showed that males accounted for $56.05 \%$ of all those surveyed in the two cities. People aged 19-35 accounted for $73.44 \%$ of the total sample, while those under 18 accounted for only $3.17 \%$, and people over 56 accounted for $7.64 \%$ of the total sample. In terms of occupations, students, enterprise employees, and government employees accounted for $78.03 \%$ of the total and are also considered to have typical commuting characteristics. People whose personal monthly incomes were less than $3000 \mathrm{RMB}$ represented the major group in this survey, with a proportion of $71.21 \%$. Based on their average daily trips, most of the people traveling 2 to 4 times a day accounted for $62.87 \%$ of the total sample. Although the sample distributions in Chongqing and Chengdu are not the same, the overall characteristics are basically consistent, as shown in Table 2.

3.4. Data Analysis. Using the two-step approach recommended by Anderson and Gerbing to evaluate the model's applicability, confirmatory factor analysis (CFA) was adopted to preprocess the measurement model [48]. SEM was then used to test model fitness and causal relationships. The correlation matrices of both the CFA and SEM were used as inputs for the analysis of moment structures (AMOS) statistical software.

Separate models were examined for both Chongqing city and Chengdu city in the measurement and structural analysis. Chi-square $\left(\chi^{2}\right)$ statistics, the goodness-of-fit index (GFI), and the root mean square of approximation (RMSEA) were used to assess how well the conceptual models represented the empirical data. For each of these test indicators, values higher than 0.9 are acceptable, with the exception of the RMSEA, for which a value greater than 0.1 indicates an acceptable fitness with the given data $[49,50]$.

\section{Results}

This study used a two-step approach to data analysis. The first step is screening the explanatory variables according to the standardized factor loadings (SFL) by running the CFA method; the second step is estimating the model using the valid set of variables, which are extracted from the first step.

4.1. Validity Verification. The results of validity test obtained from the CFA method are listed in Table 3, and all the factors passed the SFL test (less than the suggested standard value of $0.5)$, which means all the factors have passed this test. As to the overall reliability and validity of the model, the value of $\chi^{2} / \mathrm{d} f$ is 2.261 , which falls below the rigorous standard value of 3 . The other test indicators also satisfy the standard values. The RMSEA was below the standard value of 0.1 ; also, the values of GFI and normed fit index (CFI and NFI) were above the standard value of 0.9 . According to the validity test, the CFA model is thought to fit well within the data sets.

Additionally, in terms of discriminant validity, the square roots of AVE value corresponding to each latent variable were greater than the correlation coefficients of the corresponding interconstructs, which means there is discriminant validity among the variables [51]. The results are as shown in Table 4, with results obtained from both Chongqing and Chengdu satisfying the standard value of the discrepant utilities test. In sum, the hypothesized measurement model is reliable and meaningful for testing the structural relationships among the constructs. 
TABLE 1: Likert-type rating scale for variables.

\begin{tabular}{|c|c|c|}
\hline Factor & Item & Description \\
\hline Attitude & $\begin{array}{l}\text { Attitude } 1 \\
\text { Attitude } 2 \\
\text { Attitude } 3 \\
\text { Attitude } 4 \\
\text { Attitude } 5 \\
\text { Attitude } 6\end{array}$ & $\begin{array}{c}\text { Short time from departure to bus stop } \\
\text { Transfer to other bus lines or other transport modes is convenient } \\
\text { Bus service schedules are acceptable } \\
\text { Bus timetables are clear } \\
\text { Generally satisfied with the bus environment when traveling } \\
\text { Bus fare is reasonable }\end{array}$ \\
\hline Subjective norm (SN) & $\begin{array}{l}\text { SN } 1 \\
\text { SN } 2 \\
\text { SN } 3\end{array}$ & $\begin{array}{l}\text { The recommendation of taking bus obtained from family and friends works on me } \\
\text { The recommendation of taking bus obtained from TV, Internet, newspaper, etc. works on me } \\
\text { Government's priorities to bus transport will increase my willingness to use a bus }\end{array}$ \\
\hline $\begin{array}{l}\text { Perceived behavioral } \\
\text { control (PBC) }\end{array}$ & $\begin{array}{l}\text { PBC } 1 \\
\text { PBC } 2 \\
\text { PBC } 3 \\
\text { PBC } 4\end{array}$ & $\begin{array}{c}\text { High cost performance is an important factor in my choice of traveling by bus } \\
\text { Bus service is good in terms of security } \\
\text { I prefer to choose the bus if I am participating in activities with friends } \\
\text { Travel purpose affects me a lot on choosing to use the bus }\end{array}$ \\
\hline Intention & $\begin{array}{l}\text { Intention } \\
\quad 1 \\
\text { Intention } \\
\quad 2 \\
\text { Intention } \\
\quad 3 \\
\end{array}$ & $\begin{array}{c}\text { I will choose to travel by bus often in the coming year } \\
\text { Next year, I am planning to encourage others to choose the bus service } \\
\text { Next year, I will be willing to get a bus card, and I will consider traveling by bus a priority }\end{array}$ \\
\hline Behavior & $\begin{array}{l}\text { Behavior } 1 \\
\text { Behavior } 2 \\
\text { Behavior } 3\end{array}$ & $\begin{array}{l}\text { The consistency with the following description: I have been using the bus as a primary travel } \\
\text { mode for commuting in the past year. } \\
\text { The consistency with the following description: I have been using the bus as a primary travel } \\
\text { mode for entertainment in the past year. } \\
\text { The consistency with the following description: I have been using the bus as a primary travel } \\
\text { mode on business purpose in the past year. }\end{array}$ \\
\hline
\end{tabular}

TABLe 2: Statistical analysis of study participants.

\begin{tabular}{|c|c|c|c|c|c|c|c|}
\hline \multirow{2}{*}{ Variables } & \multirow{2}{*}{ Content } & \multicolumn{2}{|c|}{ Chongqing } & \multicolumn{2}{|c|}{ Chengdu } & \multicolumn{2}{|c|}{ Total } \\
\hline & & Amount & Prop. (\%) & Amount & Prop. (\%) & Amount & Prop. (\%) \\
\hline \multirow{2}{*}{ Gender } & Male & 231 & 57.61 & 246 & 54.67 & 477 & 56.05 \\
\hline & Female & 170 & 42.39 & 204 & 45.33 & 374 & 43.95 \\
\hline \multirow{4}{*}{ Age } & 18 and below & 21 & 5.24 & 6 & 1.33 & 27 & 3.17 \\
\hline & $19 \sim 35$ & 247 & 61.60 & 378 & 84.00 & 625 & 73.44 \\
\hline & $36 \sim 55$ & 83 & 20.70 & 51 & 11.33 & 134 & 15.75 \\
\hline & 56 and above & 50 & 12.47 & 15 & 3.33 & 65 & 7.64 \\
\hline \multirow{8}{*}{ Occupation } & Enterprise employee & 73 & 18.20 & 114 & 25.33 & 187 & 21.97 \\
\hline & Government employee & 38 & 9.48 & 120 & 26.67 & 158 & 18.57 \\
\hline & Student & 145 & 36.16 & 174 & 38.67 & 319 & 37.49 \\
\hline & Agricultural practitioner & 16 & 3.99 & 6 & 1.33 & 22 & 2.59 \\
\hline & Retired employee & 35 & 8.73 & 6 & 1.33 & 41 & 4.82 \\
\hline & Business/service worker & 50 & 12.47 & 18 & 4.00 & 68 & 7.99 \\
\hline & Unemployed & 19 & 4.74 & 3 & 0.67 & 22 & 2.59 \\
\hline & Others & 25 & 6.23 & 9 & 2.00 & 34 & 4.00 \\
\hline \multirow{5}{*}{ Personal monthly income (RMB) } & 1000 and below & 175 & 43.64 & 147 & 32.67 & 322 & 37.84 \\
\hline & $1001 \sim 2000$ & 33 & 8.23 & 96 & 21.33 & 129 & 15.16 \\
\hline & $2001 \sim 3000$ & 62 & 15.46 & 93 & 20.67 & 155 & 18.21 \\
\hline & $3001 \sim 4000$ & 54 & 13.47 & 72 & 16.00 & 126 & 14.81 \\
\hline & 4000 and above & 77 & 19.20 & 42 & 9.33 & 119 & 13.98 \\
\hline \multirow{3}{*}{ Average daily trips } & $0 \sim 1$ time & 117 & 29.18 & 132 & 29.33 & 249 & 29.26 \\
\hline & $2 \sim 4$ times & 256 & 63.84 & 279 & 62.00 & 535 & 62.87 \\
\hline & More than 5 times & 28 & 6.98 & 39 & 8.67 & 67 & 7.87 \\
\hline
\end{tabular}

4.2. Model Estimation. After confirming the reliability and validity of the measurements of each variable, the SEM was used to analyze the model. The maximum likelihood estimation method was used to calculate the model fitting index and the estimated value of each path coefficient, and the results are displayed in Table 5. They show that the Chi-square values of the Chongqing model and the Chengdu model are 350.610 and 362.935 , respectively, the freedom of $\chi^{2}$ is 145 in both models, and the $\chi^{2} / \mathrm{d} f$ values are 2.418 and 2.503, respectively (less than the reference 
TABLE 3: Convergent validity of results.

\begin{tabular}{|c|c|c|c|c|c|c|}
\hline Latent variable & Item & SFL & Error variance & $t$-values & $\mathrm{CR}$ & AVE \\
\hline \multirow{6}{*}{ Attitude } & Attitude 1 & 0.71 & 2.18 & - & \multirow{6}{*}{0.859} & \multirow{6}{*}{0.504} \\
\hline & Attitude 2 & 0.69 & 2.43 & 3.011 & & \\
\hline & Attitude 3 & 0.71 & 2.10 & 3.132 & & \\
\hline & Attitude 4 & 0.73 & 1.68 & 3.510 & & \\
\hline & Attitude 5 & 0.69 & 2.02 & 3.015 & & \\
\hline & Attitude 6 & 0.73 & 1.21 & 3.672 & & \\
\hline \multirow{3}{*}{ Subjective norm (SN) } & SN 1 & 0.70 & 1.03 & - & \multirow{3}{*}{0.808} & \multirow{3}{*}{0.585} \\
\hline & SN 2 & 0.82 & 0.67 & 8.539 & & \\
\hline & SN 3 & 0.77 & 1.75 & 6.022 & & \\
\hline \multirow{4}{*}{ Perceived behavioral control (PBC) } & PBC 1 & 0.68 & 1.83 & 7.160 & \multirow{4}{*}{0.803} & \multirow{4}{*}{0.505} \\
\hline & PBC 2 & 0.72 & 1.36 & 7.351 & & \\
\hline & PBC 3 & 0.74 & 1.55 & - & & \\
\hline & PBC 4 & 0.70 & 1.32 & 6.821 & & \\
\hline \multirow{3}{*}{ Intention } & Intention 1 & 0.75 & 1.56 & - & \multirow{3}{*}{0.824} & \multirow{3}{*}{0.609} \\
\hline & Intention 2 & 0.77 & 1.32 & 7.213 & & \\
\hline & Intention 3 & 0.82 & 0.81 & 8.625 & & \\
\hline \multirow{3}{*}{ Behavior } & Behavior 1 & 0.73 & 0.73 & 10.036 & \multirow{3}{*}{0.728} & \multirow{3}{*}{0.472} \\
\hline & Behavior 2 & 0.66 & 1.02 & - & & \\
\hline & Behavior 3 & 0.67 & 0.72 & 8.233 & & \\
\hline Goodness-of-fit indices & Comparativ & $\begin{array}{l}\text { idex: } \\
\mathrm{FI}=0\end{array}$ & $\begin{array}{l}.845, \mathrm{~d} f=145 \\
\text { ormed fit index: }\end{array}$ & $\begin{array}{l}001) \chi^{2} / \mathrm{d} f \\
0.927, \mathrm{~N}\end{array}$ & $\begin{array}{l}\text { 61, RM } \\
913\end{array}$ & 0.047 \\
\hline
\end{tabular}

SFL, standardized factor loading; CR, construct reliability; AVE, average variance extracted.

TABLE 4: Correlations between constructs.

\begin{tabular}{lccccc}
\hline Constructs & Attitude & SN & PBC & Intention & Behavior \\
\hline Attitude & 0.710 & & & & \\
SN & 0.365 & 0.765 & & & \\
PBC & 0.633 & 0.205 & 0.711 & & \\
Intention & 0.657 & 0.430 & 0.428 & 0.780 & \\
Behavior & 0.573 & 0.422 & 0.363 & 0.695 & 0.687 \\
\hline
\end{tabular}

Values in the diagonal are the square roots of AVE.

threshold value of 3). The RMSEA, GFI, CFI, and NFI test indicators also passed the statistical tests [50]. The model test indicators showed that the model construction is effective for the data of the two cities.

The overall standardized path coefficients $T$ values of the structural relationships among the latent variables are shown in Figure 2 According to the results, the premise proposed in the end of the review section can be confirmed in both models of the two cities, in which all the latent variables of attitude, SN, and PBC have significantly positive impacts on the intention of traveling by bus. As to the models of Chongqing and Chengdu, respectively (shown in Table 5), there are significant differences in the path coefficients of attitude-intention, SN-intention, and PBC-intention, while, in both models, PBC plays the most important role in affecting the intention of traveling by bus.

\section{Discussion and Conclusion}

This case study research incorporated the TPB and passengers' feelings toward bus transit operations into its analysis of passenger survey data from two cities. The study's findings provide further support for the predictive validity of the TPB in relation to transport mode choice (e.g., $[52,53]$ ), and the TPB variables-attitude, SN, and PBC-showed significance in predicting bus choice behavior according to the convergent validity tests summarized in Table 3. The findings also verified the effectiveness of the TPB framework, and the significant discrepancy in the results for the two different cities confirmed the validity of the measurement variables.

The most important variable in predicting travel intentions was PBC, and this finding is also supported by other research. For example, Wall et al. found that $\mathrm{PBC}$ and moral norms are the only variables that influence the intention to travel by driving [53]. Harland et al. found that PBC is the strongest factor for explaining the intention to travel by bus or private car [54]. Although the measurement variables used to describe PBC vary by model, they represent equivalent meanings to passengers in the used scenarios as well as the importance of travel plans. A key difference between this study and previous research is that this study measures $\mathrm{PBC}$ variables by considering the characteristics of travel by bus mode and then applies the model to two cities with significantly different characteristics. The results confirmed that PBC factors play important roles in considering and deciding to travel by bus mode. According to the results, although the effect of PBC on the final behavior of traveling by bus is at the same level in the two cities, the effect on the intention is considerably different. In the Chongqing sample, PBC's effect on intention is considerably stronger than that in the Chengdu sample. This result may indicate some difference in the characteristics of the two cities' resident. In terms of travel mode choice, Chongqing people show a stronger assertiveness than Chengdu people. This difference is also consistent with the general perception, given by the 
TABLE 5: Structural parameter estimates and goodness-of-fit indices.

\begin{tabular}{|c|c|c|c|}
\hline Path & Overall & Model of Chongqing city & Model of Chengdu city \\
\hline Attitude $\longrightarrow$ Intention & $0.236\left(3.210^{* *}\right)$ & $0.115\left(2.106^{*}\right)$ & $0.272\left(2.890^{* *}\right)$ \\
\hline $\mathrm{SN} \longrightarrow$ Intention & $0.143\left(2.135^{*}\right)$ & $0.095\left(2.157^{*}\right)$ & $0.158\left(2.311^{*}\right)$ \\
\hline $\mathrm{PBC} \longrightarrow$ Intention & $0.670\left(4.612^{* *}\right)$ & $0.784\left(5.423^{* *}\right)$ & $0.588\left(5.267^{* *}\right)$ \\
\hline $\mathrm{PBC} \longrightarrow$ Behavior & $0.533\left(4.176^{* *}\right)$ & $0.501\left(4.143^{* *}\right)$ & $0.523\left(4.098^{* *}\right)$ \\
\hline Intention $\longrightarrow$ Behavior & $0.782\left(8.207^{* *}\right)$ & $0.842\left(7.415^{* *}\right)$ & $0.759\left(6.739^{* *}\right)$ \\
\hline Goodness-of-fit index & $\begin{array}{c}\chi^{2}=327.845 \\
d f=145(p<0.001) \\
\chi^{2} / d f=2.261 \\
\text { RMSEA }=0.047 \\
\text { GFI }=0.922 \\
\text { CFI }=0.927 \\
\text { NFI }=0.913\end{array}$ & $\begin{array}{c}\chi^{2}=350.610 \\
d f=145(p<0.001) \\
\chi^{2} / d f=2.418 \\
\text { RMSEA }=0.046 \\
\text { GFI }=0.911 \\
\text { CFI }=0.906 \\
\text { NFI }=0.912\end{array}$ & $\begin{array}{c}\chi^{2}=362.935 \\
d f=145(p<0.001) \\
\chi^{2} / d f=2.503 \\
\text { RMSEA }=0.047 \\
\text { GFI }=0.902, \\
\text { CFI }=0.928 \\
\text { NFI }=0.925\end{array}$ \\
\hline
\end{tabular}

${ }^{*} p<0.05 ;{ }^{* *} p<0.01$.

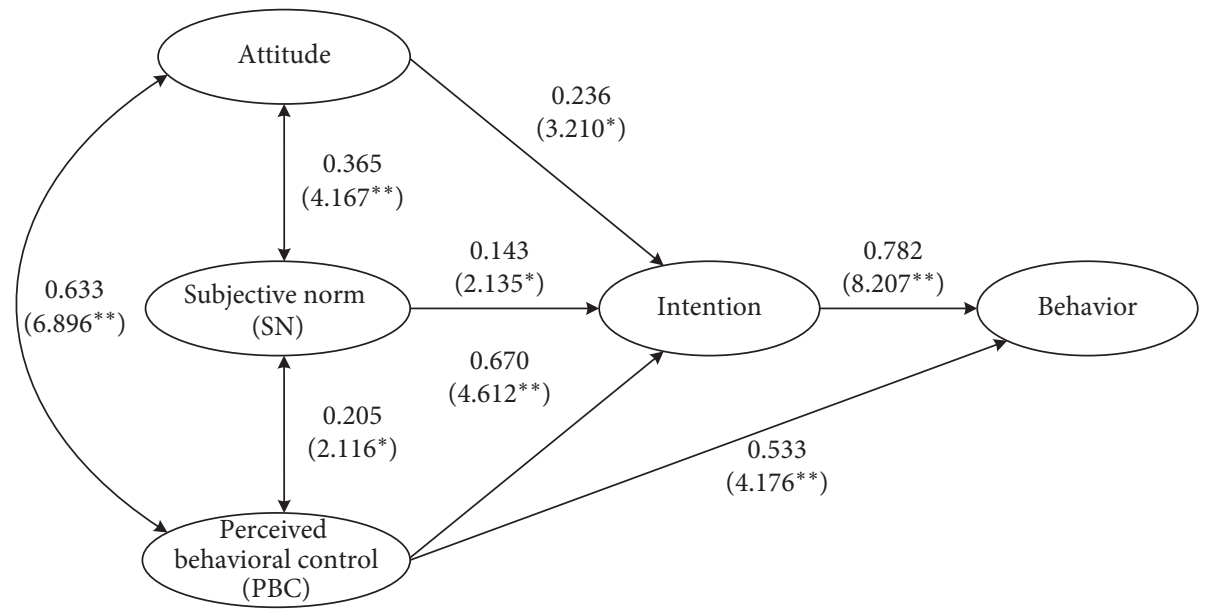

Figure 2: Estimated model of Chongqing and Chengdu.

two cities' people, that Chongqing tends to be straightforward, while Chengdu is more tactful.

Attitude to the quality of bus service is also an important factor influencing the intention of using a bus, which is also widely accepted by scholars. But the effect is not exactly at the same level in different study cases and travel modes, especially in the case of choosing a car as the travel mode $[28,55]$. In this study, the same model running on two sets of data gave two significantly different relationships between attitude and intention. For people living in Chongqing, their intentions of using a bus are significantly less influenced by the attitude to bus service than those in Chengdu. This difference in the sensitiveness to the quality of bus services is probably caused by the difference in alternative travel mode options. Since Chengdu is a typical plain city, cycling and walking are usually used as the general travel mode in the case of short-distance travel. Especially in the context that bicyclesharing is very common in most China's cities, cycling has become a good alternative to short-distance bus travel. But the situation is different in Chongqing. As a typical mountain city, cycling is generally treated as a form of sports rather than a travel mode; people have few choices for short-distance travel. Therefore, the quality of service is no longer important for people choosing a bus in Chongqing.
This study's findings that SN factors are weak in predicting behavioral intentions are consistent with those of previous research, and the contribution of $\mathrm{SN}$ is weakest in both two models [31]. This result indicates that, with regard to the issue of bus choice behavior, the opinions of one's friends and family, media campaigns, and government policy guidelines have limited influence, while travelers' attitudes and perceptions more strongly influence their own attitudes toward the bus and their perceptions of the service. Comparing the coefficients of $\mathrm{SN}$ in both models, it is significantly higher in Chengdu than that in Chongqing. This result is also consistent with the coefficient of PBC in this study that Chongqing people showed a stronger assertiveness than Chengdu people. Thus, the comments from others or media work less on Chongqing people. Although $\mathrm{SN}$ is not a strong predictor in the models, the difference in the coefficients can partly reflect the difference in the characteristics between the two cities.

Overall, the effects of psychological factors via intention to the behavior of using a bus are verified in both two cities. The TPB framework and explanatory indicators maintain consistent effectiveness in both models and showed significant differences in both cities. The results of this study indicate that transport conditions and resident 
characteristics are also important factors influencing the process of making the decision of using a bus. When proposing specific measures to promote the use of public transport, it is more appropriate to take different measures based on the cities' characteristics. For example, in this study, the quality of bus services in Chongqing is no longer important because of the poor substitutability in public transport. Coupled with the strong personality of Chongqing people (not easy to be affected by advertising), coverage and capacity (frequency) improvement of the bus will become more effective. But regarding Chengdu, on the contrary, due to the direct competition between bike-sharing and bus on short-distance travel, improving the quality of bus services plays a more important role in increasing the bus competitiveness. In addition, Chengdu people are more likely to accept external information, which also makes advertising more effective. Acknowledging that passengers' feelings are the most important factor influencing their decisions to travel by bus can provide new avenues for enhancing the attractiveness of bus service, also increasing the participation rate.

\section{Data Availability}

The data used in the study are available upon request.

\section{Conflicts of Interest}

The authors declare no conflicts of interest.

\section{Authors' Contributions}

Jian Chen and He-ping Li contributed to study conception and design. Jian Chen performed data collection. Jian Chen and Qi Chen performed analysis and interpretation of results. Qi Chen and Jian Chen performed draft manuscript preparation. All authors reviewed the results and approved the final version of the manuscript.

\section{Acknowledgments}

The authors wish to express their appreciation to Chinese National Funding of Social Sciences (17XGL009) for sponsoring this research.

\section{References}

[1] C. M. Collins and S. M. Chambers, "Psychological and situational influences on commuter-transport-mode choice," Environment and Behavior, vol. 37, no. 5, pp. 640-661, 2005.

[2] M. A. Tarrant and H. K. Cordell, "The effect of respondent characteristics on general environmental attitude-behavior correspondence," Environment and Behavior, vol. 29, no. 5, pp. 618-637, 1997.

[3] S. G. Stradling, "Chapter 34-travel mode choice," in Handbook of Traffic Psychology, pp. 485-502, Academic Press, Cambridge, MA, USA, 2011.

[4] D. McFadden, "Conditional Logit Analysis of Qualitative Choice Behavior," in Frontiers in Econometrics, pp. 105-142, Academic Press, Salt Lake City, Utah, 1974.
[5] J. de Dios Ortuzar, "Nested logit models for mixed-mode travel in urban corridors," Transportation Research Part A: General, vol. 17, no. 4, pp. 283-299, 1983.

[6] F. S. Koppelman and C.-H. Wen, "Alternative nested logit models: structure, properties and estimation," Transportation Research Part B: Methodological, vol. 32, no. 5, pp. 289-298, 1998.

[7] M. Polk, "The influence of gender on daily car use and on willingness to reduce car use in Sweden," Journal of Transport Geography, vol. 12, no. 3, pp. 185-195, 2004.

[8] C. Liu, Y. O. Susilo, and A. Karlström, "The influence of weather characteristics variability on individual's travel mode choice in different seasons and regions in Sweden," Transport Policy, vol. 41, pp. 147-158, 2015.

[9] D. A. Hensher and J. M. Rose, "Development of commuter and non-commuter mode choice models for the assessment of new public transport infrastructure projects: a case study," Transportation Research Part A: Policy and Practice, vol. 41, no. 5, pp. 428-443, 2007.

[10] P. W. Wilson, "Scheduling costs and the value of travel time," Urban Studies, vol. 26, no. 3, pp. 356-366, 1989.

[11] W. L. Jeski, "New findings on factors related to transit use," Ite Journal, vol. 60, no. 2, 1990.

[12] I. Fenwick, R. Heeler, and P. Simmie, "Switching commuters from car to public transit: a micro modelling approach," Journal of Economic Psychology, vol. 3, no. 3-4, pp. 333-345, 1983.

[13] D. A. Hensher and A. J. Reyes, "Trip chaining as a barrier to the propensity to use public transport," Transportation, vol. 27, no. 4, pp. 341-361, 2000.

[14] R. Mitra and R. N. Buliung, "Exploring differences in school travel mode choice behaviour between children and youth," Transport Policy, vol. 42, pp. 4-11, 2015.

[15] A. de Palma and D. Rochat, "Mode choices for trips to work in Geneva: an empirical analysis," Journal of Transport Geography, vol. 8, no. 1, pp. 43-51, 2000.

[16] I. J. Donald, S. R. Cooper, and S. M. Conchie, “An extended theory of planned behaviour model of the psychological factors affecting commuters' transport mode use," Journal of Environmental Psychology, vol. 40, pp. 39-48, 2014.

[17] L. Steg, "Car use: lust and must. Instrumental, symbolic and affective motives for car use," Transportation Research Part A: Policy and Practice, vol. 39, no. 2-3, pp. 147-162, 2005.

[18] S. Stradling, M. Carreno, T. Rye, and A. Noble, "Passenger perceptions and the ideal urban bus journey experience," Transport Policy, vol. 14, no. 4, pp. 283-292, 2007.

[19] M. Ben-Akiva, J. Walker, A. T. Bernardino, D. A. Gopinath, T. Morikawa, and A. Polydoropoulou, "Integration of choice and latent variable models," In Perpetual Motion, Elsevier, Amsterdam, Netherlands, pp. 431-470, 2002.

[20] M. V. Johansson, T. Heldt, and P. Johansson, "The effects of attitudes and personality traits on mode choice," Transportation Research Part A: Policy and Practice, vol. 40, no. 6, pp. 507-525, 2006.

[21] M. F. Yáñez, S. Raveau, and J. d. D. Ortúzar, "Inclusion of latent variables in mixed logit models: modelling and forecasting," Transportation Research Part A: Policy and Practice, vol. 44, no. 9, pp. 744-753, 2010.

[22] L. Redman, M. Friman, T. Gärling, and T. Hartig, "Quality attributes of public transport that attract car users: a research review," Transport Policy, vol. 25, pp. 119-127, 2013.

[23] Ö. Şimşekoğlu, T. Nordfjærn, and T. Rundmo, "The role of attitudes, transport priorities, and car use habit for travel mode use and intentions to use public transportation in an urban Norwegian public," Transportation (Amst)., vol. 42, pp. 113-120, 2015. 
[24] M. Hunecke, S. Haustein, S. Böhler, and S. Grischkat, "Attitude-based target groups to reduce the ecological impact of daily mobility behavior," Environment and Behavior, vol. 42, no. 1, pp. 3-43, 2010.

[25] I. Ajzen, "The theory of planned behavior," Organizational Behavior and Human Decision Processes, vol. 50, no. 2, pp. 179-211, 1991.

[26] S. Bamberg, I. Ajzen, and P. Schmidt, "Choice of travel mode in the theory of planned behavior: the roles of past behavior, habit, and reasoned action," Basic and Applied Social Psychology, vol. 25, no. 3, pp. 175-187, 2003.

[27] S. Bamberg and P. Schmidt, "Theory-driven subgroup-specific evaluation of an intervention to reduce private car use," Journal of Applied Social Psychology, vol. 31, no. 6, pp. 1300-1329, 2001.

[28] S. H. Lo, G. J. P. van Breukelen, G.-J. Y. Peters, and G. Kok, "Commuting travel mode choice among office workers: comparing an extended theory of planned behavior model between regions and organizational sectors," Travel Behaviour and Society, vol. 4, pp. 1-10, 2016.

[29] I. Ajzen, "From intentions to actions: a theory of planned behavior," in Action Control, pp. 11-39, Springer, Berlin, Germany, 1985.

[30] R. J. Hill, M. Fishbein, and I. Ajzen, "Belief, attitude, intention, and behavior: an introduction to theory and research," Contemporary Sociology, vol. 6, no. 2, p. 244, 1977.

[31] C. J. Armitage and M. Conner, "Efficacy of the theory of planned behaviour: a meta-analytic review," British Journal of Social Psychology, vol. 40, no. 4, pp. 471-499, 2001.

[32] M. Conner and C. J. Armitage, "Extending the theory of planned behavior: a review and avenues for further research," Journal of Applied Social Psychology, vol. 28, no. 15, pp. 1429-1464, 1998.

[33] G. Godin and G. Kok, "The theory of planned behavior: a review of its applications to health-related behaviors," American Journal of Health Promotion, vol. 11, no. 2, pp. 87-98, 1996.

[34] S. Bamberg, "The promotion of new behavior by forming an implementation intention: results of a field experiment in the domain of travel mode choice," Journal of Applied Social Psychology, vol. 30, no. 9, pp. 1903-1922, 2000.

[35] M. Hunecke, A. Blöbaum, E. Matthies, and R. Höger, "Responsibility and environment: ecological norm orientation and external factors in the domain of travel mode choice behavior," Environment and Behavior, vol. 33, no. 6, pp. 830-852, 2001.

[36] K. A. Bollen, "Latent variables in psychology and the social sciences," Annual Review of Psychology, vol. 53, no. 1, pp. 605-634, 2002.

[37] T. F. Golob, "Structural equation modeling for travel behavior research," Transportation Research Part B: Methodological, vol. 37, no. 1, pp. 1-25, 2003.

[38] S. W. Huck, W. H. Cormier, and W. G. Bounds, Reading Statistics and Research, Harper \& Row, New York, NY, USA, 1974.

[39] W. T. Bielby and R. M. Hauser, "Structural equation models," Annual Review of Sociology, vol. 3, no. 1, pp. 137-161, 1977.

[40] J. Gould and T. F. Golob, "Shopping without travel or travel without shopping? An investigation of electronic home shopping," Transport Reviews, vol. 17, no. 4, pp. 355-376, 1997.

[41] C. Jakobsson, S. Fujii, and T. Gärling, "Determinants of private car users' acceptance of road pricing," Transport Policy, vol. 7, no. 2, pp. 153-158, 2000.
[42] H. T. Van and S. Fujii, "A cross Asian country analysis in attitudes toward car and public transport," in Proceedings of the 9th International Conference of Eastern Asia Society for Transportation Studies, p. 87, Jeju-do, South Korea, June 2011.

[43] L. Y. L. Loo, J. Corcoran, D. Mateo-Babiano, and R. Zahnow, "Transport mode choice in South East Asia: investigating the relationship between transport users' perception and travel behaviour in Johor Bahru, Malaysia," Journal of Transport Geography, vol. 46, pp. 99-111, 2015.

[44] China Urban Rail Transit Association, Urban Rail Transit 2018 Annual Statistics and Analysis Report, Beijing, China, 2019, in Chinese.

[45] Chongqing Transport Planning Institute, 2018 Chongqing Urban Traffic Annual Report, Chongqing Transport Planning Institute, Chongqing, China, 2018, in Chinese.

[46] R. B. Kline and D. A. Santor, "Principles \& practice of structural equation modelling," Canadian Psychology, vol. 40, no. 4, p. 381, 1999.

[47] D. Soper, "A-priori sample size calculator for hierarchical multiple regression," 2011.

[48] J. C. Anderson and D. W. Gerbing, "Structural equation modeling in practice: a review and recommended two-step approach," Psychological Bulletin, vol. 103, no. 3, pp. 411-423, 1988.

[49] C.-F. Chen and W.-H. Chao, "Habitual or reasoned? Using the theory of planned behavior, technology acceptance model, and habit to examine switching intentions toward public transit," Transportation Research Part F: Traffic Psychology and Behaviour, vol. 14, no. 2, pp. 128-137, 2011.

[50] J. F. Hair, W. C. Black, B. J. Babin, R. E. Anderson, and R. L. Tatham, Multivariate Data Analysis, Prentice-Hall, Upper Saddle River, NJ, USA, 1998.

[51] C. Fornell and D. F. Larcker, "Evaluating structural equation models with unobservable variables and measurement error," Journal of Marketing Research, vol. 18, no. 1, pp. 39-50, 1981.

[52] S. Bamberg and P. Schmidt, "Incentives, morality, or habit? Predicting students' car use for university routes with the models of ajzen, schwartz, and triandis," Environment and Behavior, vol. 35, no. 2, pp. 264-285, 2003.

[53] R. Wall, P. Devine-Wright, and G. A. Mill, "Comparing and combining theories to explain proenvironmental intentions: the case of commuting-mode choice," Environment and Behavior, vol. 39, no. 6, pp. 731-753, 2007.

[54] P. Harland, H. Staats, and H. A. M. Wilke, "Explaining proenvironmental intention and behavior by personal norms and the theory of planned behavior," Journal of Applied Social Psychology, vol. 29, no. 12, pp. 2505-2528, 1999.

[55] S. Bamberg, M. Hunecke, and A. Blöbaum, "Social context, personal norms and the use of public transportation: two field studies," Journal of Environmental Psychology, vol. 27, no. 3, pp. 190-203, 2007. 